Fukushima J. Med. Sci.,

Vol. 59, No. 1, 2013

[Case Report]

\title{
TWO CASES OF MIXED CONNECTIVE TISSUE DISEASE COMPLICATED WITH THROMBOTIC THROMBOCYTOPENIC PURPURA
}

\author{
EIJI SUZUKI ${ }^{12)}$, TAKASHI KANNO ${ }^{1)}$, TOMOYUKI ASANO ${ }^{12)}$, AKITO TSUTSUMI $^{3)}$, \\ HIROKO KOBAYASHI ${ }^{2)}$, HIROSHI WATANABE ${ }^{2)}$ and HIROMASA OHIRA ${ }^{2)}$ \\ ${ }^{1)}$ Division of Rheumatology, Ohta-Nishinouchi Hospital, Koriyama, Japan, ${ }^{2)}$ Department of Gastroenter- \\ ology and Rheumatology, Fukushima Medical University School of Medicine, Fukushima, Japan, ${ }^{3)}$ Taki- \\ kawa Municipal Hospital, Takikawa, Japan
}

(Received August 16, 2012, accepted January 21, 2013)

\begin{abstract}
Thrombotic thrombocytopenic purpura (TTP) is a rare complication of connective tissue diseases. Here, we describe 2 patients with mixed connective tissue disease (MCTD) who had pericardial effusion and TTP. They had moderately low to normal ADAMTS13 activity and no ADAMTS13 neutralizing antibodies. Both patients responded poorly to plasma exchange. One patient died due to multiple organ failure and the other due to infection. Although rare, TTP is an important complication that leads to a poor prognosis in MCTD patients.
\end{abstract}

Key words : a disintegrin-like metalloproteinase with thrombospondin type 1 motifs 13 (ADAMTS13), mixed connective tissue disease (MCTD), pericardial effusion, thrombotic thrombocytopenic purpura (TTP)

\section{INTRODUCTION}

Thrombotic thrombocytopenic purpura (TTP) is a microvascular occlusive disorder characterized by a pentad of signs and syndromes, including microangiopathic hemolytic anemia with the presence of fragmented red cells, thrombocytopenia, fever, renal failure and neurological abnormalities. Although the pathogenesis of TTP has not been completely elucidated, TTP is known to occur in association with connective tissue diseases (CTD), infections and some drugs ${ }^{1}$. It has been shown that severe deficiency of the plasma von Willebrand factor (vWF) cleaving metalloprotease, ADAMTS13 (a disintegrin-like metalloproteinase with thrombospondin type 1 motifs 13), activity is important in the pathogenesis of $\mathrm{TTP}^{2)}$. Although plasma exchange (PE) is known to be effective and is recommended as the first treatment for TTP, PE and other treatments such as immnosuppressive drugs are often not effective in patients with refractory TTP.

Mixed connective tissue disease (MCTD) is a disease that has combined features of systemic lupus erythematosus (SLE), systemic sclerosis (SSc), polymyositis/dermatomyositis, and is characterized by high titers of serum antibodies to the U1 small nuclear ribonucleoprotein (RNP). Although the 10-year survival rate of MCTD patients is relatively high at around $80 \%$, prognosis can vary depending on the CTD that may eventually develop ${ }^{3}$. While a fairly large number of SLE or SSc patients complicated with TTP have been reported ${ }^{4,5}$, only a few reports of MCTD patients with TTP exist. According to these reports, many patients had a poor prognosis, despite various aggressive treatments including $\mathrm{PE}^{6-17)}$.

We describe herein two patients with MCTD who had a sudden onset of TTP. We also discuss the diagnosis and management of MCTD patients complicated with TTP, with reference to the relevant literature.

Corresponding author : Eiji Suzuki E-mail address : azsuzuki@fmu.ac.jp

https://www.jstage.jst.go.jp/browse/fms http://www.fmu.ac.jp/home/lib/F-igaku/ 


\section{CASE REPORT}

\section{Case 1}

A 47-year-old Japanese woman was admitted to our hospital on December 26, 2007 because of severe dyspnea and generalized edema. A diagnosis of MCTD was made because of facial erythema, Raynaud's phenomenon and positivity for serum anti-RNP antibody. Prednisolone was administered in 1994, but was soon discontinued. In 2002, interstitial pneumonia became evident, and administration of prednisolone was resumed, but was soon discontinued. In September 2007, high grade fever and cough developed, and she entered a nearby hospital. Prednisolone (40 mg/day) and antibiotics were given, but dyspnea and edema gradually developed. She visited our hospital in December 2007.

Physical examination on admission showed malar rash as well as erythema of the dorsum of bilateral elbows and close to the nails. Furrows around her mouth perpendicular to her lips and sclerodactyly were present. Auscultation of the chest identified audible fine crackles in the lower aspects of both lungs. The results of laboratory studies performed on admission were as follows: white blood cell (WBC) count was slightly high at $9,300 / \mu \mathrm{l}$; hemoglobin was normal at $13.3 \mathrm{~g} / \mathrm{dl}$; and platelet count was slightly high at $430,000 / \mu 1$. Coagulation tests were normal. Lactate dehydrogenase $(\mathrm{LDH})$, brain natriuretic peptide and KL-6 were elevated at $302 \mathrm{IU} / 1,27 \mathrm{pg} / \mathrm{ml}$ and 2,180 U/ml, respectively. Renal function tests were normal. C-reactive protein (CRP) was normal. Immunoglobulin $\mathrm{G}$ was high at $2,881 \mathrm{mg} / \mathrm{dl}$; Immuno- globulin A was high at $470 \mathrm{mg} / \mathrm{dl}$. Anti-nuclear antibody was positive at a titer of $1: 320$ (speckled pattern), and anti-U1RNP antibody was positive at a titer of $1: 8$, but other specific antibodies including anti-DNA and antiphospholipid antibodies were not detected. Urinalysis tests were normal. Chest $\mathrm{X}$-ray findings showed enlargement of the cardiac shadow (Fig. 1a). Cardiac ultrasound revealed a large amount of pericardial effusion. Chest computed tomography (CT) showed massive pericardial effusion (Fig. 1b), and lung fibrosis, especially in the lower lobes.

Drainage of the pericardial effusion $(750 \mathrm{ml})$ was performed, and she was given intravenous methyl-prednisolone (1,000 mg/day) for 3 days, followed by $60 \mathrm{mg} /$ day oral prednisolone. Her pericardial effusion almost disappeared. However, hemolytic urine and nasal bleeding developed on January 11, 2008. The results of laboratory studies performed at that time were as follows : WBC count was $11,400 / \mu 1$; red blood cell count, hemoglobin and hematocrit were decreased at $3.68 \times 10^{6} / \mu 1,10.7$ $\mathrm{g} / \mathrm{dl}$ and $32.6 \%$, respectively. The reticulocyte ratio was elevated at $109 \%$. Platelet count fell to $55,000 / \mu 1$. A peripheral blood smear showed many $(>100)$ schistocytes per field. Fibrin/fibrinogen degradation products and D-dimer were slightly elevated at $5.5 \mu \mathrm{g} / \mathrm{dl}$ and $2.1 \mu \mathrm{g} / \mathrm{ml}$, but other coagulation tests were almost normal. Total bilirubin and indirect bilirubin were elevated at 2.76 and $2.52 \mathrm{mg} /$ dl, respectively. Aspartate aminotransferase (AST) and LDH were elevated at 49 and 3140 IU/1, respectively. Blood urea nitrogen (BUN) was elevated at $42.8 \mathrm{mg} / \mathrm{dl}$, but creatinine was normal at $0.38 \mathrm{mg} / \mathrm{dl}$. Haptoglobin was undetectable. Albuminuria and a

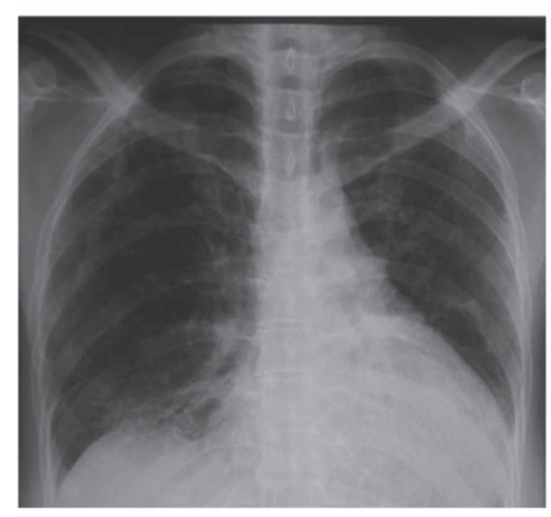

b

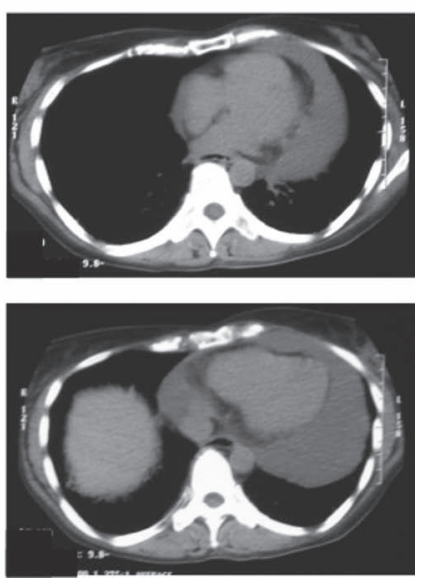

Fig. 1. a : Chest radiograph of case 1 on admission showing cardiac enlargement and bilateral interstitial shadows. b : Chest computed tomography on admission showing massive pericardial effusion. 
hematuria were apparent in urinalysis. ADAMTS13 activity was $114.3 \%$ and antibodies to ADAMTS13 were not detected on January 17, 5 days after the first PE.

Although there was no fever or neurological symptoms, a diagnosis of TTP was made because of the presence of hemolytic anemia with fragmented cells, thrombocytopenia and renal failure. Daily PE was carried out for 5 days starting on January 12 , after which $\mathrm{PE}$ was continued 3 days per week (fresh frozen plasma, 3,200 $\mathrm{ml}$ per $\mathrm{PE}$ was used). In spite of continuous PE and high-dose prednisolone treatment, her renal failure aggravated, and she underwent hemodialysis and another PE. Her platelet count gradually increased during the last 10 days of February, but she developed esophageal bleeding and pneumothorax. She died on March 22 due to multiple organ failure.

Case 2

A 61-year-old Japanese woman visited the emergency room of our hospital on December 22, 2009 because of dyspnea, edema and a nonambulatory state. She was diagnosed with SSc when she was 51 years old based on sclerodactyly, Raynaud's phenomenon and positivity for serum anti-nuclear antibody, and was admitted to our division on an irregular basis. In October 2009, she experienced lumbago and lower leg pain, and was admitted to the division of orthopedics where she was diagnosed as having herniated lumber discs. She was given non-steroidal anti-inflammatory drugs, but her pain did not improve. Her state worsened, showing obvious face and leg edema.

Physical examination on admission showed face and bilateral leg edema, erythema of the dorsum of bilateral elbows, heliotrope rash, Gottron's sign and sclerodactyly. Blood pressure was 157/80 mmHg and oxygen saturation was $96 \%$. The results of laboratory studies performed on admission were as follows: WBC count was normal at $6,700 / \mu 1$; hemoglobin was low at $8.1 \mathrm{~g} / \mathrm{dl}$; and platelet count was low at 78,000/ $\mu$ l. Fibrin/fibrinogen degradation products and $\mathrm{D}$-dimer were slightly elevated at 6.5 $\mu \mathrm{g} / \mathrm{dl}$ and $3.8 \mu \mathrm{g} / \mathrm{ml}$, respectively, but other coagulation tests were normal. AST, alanine aminotransferase, $\mathrm{LDH}$ and creatine kinase were elevated at 331, 118, 1,492 and 4,699 IU/1, respectively. BUN and creatinine were elevated at 27.5 and $1.24 \mathrm{mg} / \mathrm{dl}$, respectively. Serum CRP level was normal. Immunoglobulin $\mathrm{G}$ was high at $3,256 \mathrm{mg} / \mathrm{dl}$; Complement value (CH50) was $19.9 \mathrm{U} / \mathrm{ml}$, C3 was $35 \mathrm{mg} / \mathrm{dl}$, and $\mathrm{C} 4$ was $6 \mathrm{mg} / \mathrm{dl}$, which were all low. Anti-nuclear antibody was positive at a titer of $1: 2,560$ (speckled pattern), anti-DNA antibody (Radioimmunoassay) was elevated at $15 \mathrm{IU} / \mathrm{ml}$, antiU1RNP antibody was positive at a titer of $1: 128$, and anti-SS-A antibody was positive at a titer of $1: 4$, but anti-Jo1 antibody was negative. Albuminuria and hematuria were detected in urinalysis. A chest CT showed bilateral pleural effusion. An echocardiogram showed a moderate amount of pericardial effusion, left ventricular hypertrophy and a moderate grade of mitral regurgitation.

Although a skin lesion and elevated creatine kinase were observed, the patient could not be diag-

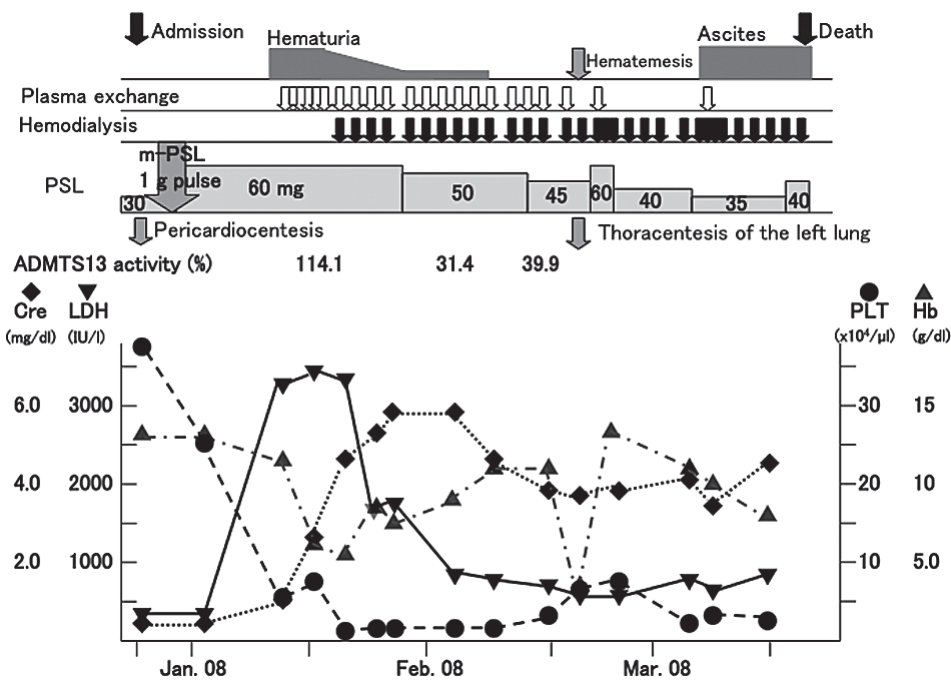

Fig. 2. Clinical course of case 1 after admission. m-PSL, methyl prednisolone ; PSL, prednisolone ; ADAMTS13, a disintegrin and metalloprotease with a thrombospondin-1 like domain; $C r e$, creatinine; $L D H$, lactic dehydrogenase ; PLT, platelets ; $H b$, hemoglobin. 


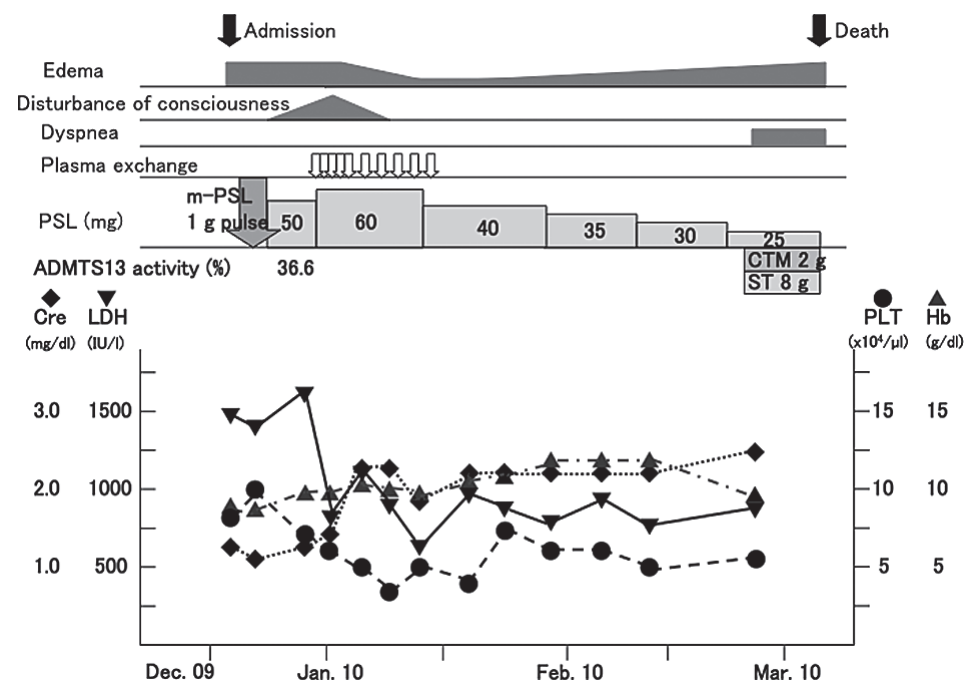

Fig. 3. Clinical course of case 2 after admission. $m$-PSL, methyl prednisolone; $P S L$, prednisolone; CTM, Cefotiam ; ST, Trimethoprim-Sulfamethoxazole ; ADAMTS13, a disintegrin and metalloprotease with a thrombospondin-1 like domain ; $C r e$, creatinine ; $L D H$, lactic dehydrogenase ; PLT, platelets ; $H b$, hemoglobin.

nosed as having dermatomyositis. She fulfilled the classification criteria for SLE (citation) based on pleuritis, low platelet count, and positivity for serum antinuclear antibody and anti-DNA antibody. However, the titer of anti-DNA antibody was not very high, and various possible causes of pleuritis other than SLE were considered. On the other hand, her anti-U1 RNP antibody titer was high, and her symptoms and laboratory examination fulfilled the diagnostic criteria of MCTD (citation). Therefore, the patient was re-diagnosed as having MCTD. She received $1,000 \mathrm{mg}$ /day intravenous methyl-prednisolone for 3 days, followed by $60 \mathrm{mg} /$ day oral prednisolone. However, her physical condition deteriorated, with decreased urine volume and increased systolic blood pressure to approximately $180 \mathrm{mmHg}$. Laboratory examination revealed hemolytic anemia (the ratio of reticulocyte was elevated at $183 \%$, total bilirubin was elevated at $2.0 \mathrm{mg} / \mathrm{dl}$, and haptoglobin was not detected, although direct and indirect Coombs tests were negative), thrombocytopenia (platelet count was 66,000/ $\mu \mathrm{l})$, and progression of renal failure. A peripheral blood smear showed five to six schistocytes per field. On December 28, her consciousness level worsened. ADAMTS13 activity was low at $36.6 \%$ and antibodies to ADAMTS13 were not detected. A diagnosis of TTP was made, and PE with $3,200 \mathrm{ml}$ of fresh frozen plasma, was immediately started. After treatment, she regained consciousness and her blood pressure went down. However, renal failure and thrombocytopenia did not improve. PE was discontinued after 10 treatments because her general condition had improved. The dose of prednisolone was gradually tapered. In late February 2010, she had a sudden onset of dyspnea. Chest $\mathrm{X}$-ray and chest CT showed interstitial shadows in both lungs. $\beta$-D-glucan was positive at $58.8 \mathrm{pg} /$ $\mathrm{ml}$. Pneumocystis jiroveci pneumonia was highly suspected. Trimethoprim-sulfamethoxazole in combination with antibiotics was given, but her general condition worsened, and she died on March 2.

\section{DISCUSSION}

Although the pathogenesis of TTP has not been clearly elucidated, recent studies have shown that severe deficiency of ADAMTS13 activity plays an important role in the pathogenesis of $\mathrm{TTP}^{2}$. Absent or severely reduced activity of ADAMTS13 in patients with TTP impairs the timely cleavage of unusually large multimers of vWF when they are secreted by endothelial cells. Uncleaved multimers induce adhesion and aggregation of platelets in the blood flow. An acquired defect of ADAMTS13 activity, such as that caused by anti-ADAMTS13 autoantibodies, can lead to TTP ${ }^{18)}$. Systemic microvascular aggregation of platelets in TTP patients causes ischemia in the brain and other organs. TTP and hemolytic uremic syndrome (HUS) are two typical phenotypes of thrombotic microangiopathies (TMAs). Although severe deficiency of plasma ADAMTS13 activity is more common in TTP, it is difficult to distinguish between TTP and HUS.

Acquired TMAs can be classified into 2 catego- 
ries, idiopathic and secondary TMAs. Causes of secondary TMAs include medication, infection, malignancy and other various underlying diseases. CTDs are also recognized as an important cause of secondary TMAs. There are some reports of patients with SLE complicated with TTP ${ }^{19}$. SLE and TTP have similar symptoms, such as hemolytic anemia, thrombocytopenia, renal dysfunction and neurological symptoms. Differential diagnosis is difficult in some cases, but is very important, because the treatments are quite different. Matsuyama et al. recently reported on thrombotic microangiopathies (TMA) in patients with CTDs including SLE, SSc, polymiositis/dermatomyositis, and rheumatoid arthritis, but patients with MCTD were not included in their study. In this report, they classified TMAs in patients with CTDs into two categories: a minor population with ADAMTS13 activity that was almost completely inhibited by neutralizing autoantibodies, and a major population with normal or moderately reduced activity. The former group had a better therapeutic outcome than the latter ${ }^{20)}$, i.e., the prognosis of CTD-TMA patients was worse compared to that of acquired idiopathic TTP patients.

Few MCTD patients with TTP complication have been reported. We have summarized the 14 patients reported, including our 2 cases, in Table 1 (including Japanese literature). All except one case were women, and the age and duration of MCTD varied considerably. The patients were treated mainly with prednisolone and PE. Eight patients died despite intensive treatment. ADAMTS13 activity and neutralizing antibodies were measured in very few patients. Past case reports showed that prognosis of MCTD could be far worse when accompanied by neurological manifestations of $\mathrm{TTP}^{14)}$. Another report showed that existence of refractory pericardial effusion indicated dysfunction of microcirculation $^{11)}$; thus, this symptom might also be a sign of worse prognosis. Although extremely rare in MCTD patients, TTP is a complication that has one of the worst prognoses. Although a standard protocol for treatment of this condition has not been established, it is clear that early diagnosis and treatment would lead to a better prognosis.

It is difficult to clarify the underlying mechanisms that cause CTD-TMAs. Some CTD patients, especially MCTD patients, have complications of pulmonary hypertension ${ }^{3}$. A higher prevalence of anti-endothelial antibodies has been reported in sera obtained from MCTD patients ${ }^{211}$. These data might suggest that endothelial cell abnormalities such as endothelial cell proliferation and endothelial cell injury exist in these patients. Matsuyama et al. suggested that impaired vascular endothelial function due to vasculitis caused by CTDs might prevent the efficient cleavage of unusually large vWF multimers by ADAMTS13. They also suggested that narrowed vessel cavities in CTD patients that are due to the proliferation of vascular endothelial cells generate

Table 1. Complication of thrombotic thrombocytopenic purpura in patients with mixed connective tissue disease.

\begin{tabular}{|c|c|c|c|c|c|c|c|c|}
\hline Case & Age/Sex & $\begin{array}{l}\text { Duration of } \\
\text { MCTD }\end{array}$ & $\begin{array}{c}\text { Renal } \\
\text { involvement }\end{array}$ & $\begin{array}{l}\text { Neurological } \\
\text { symptoms }\end{array}$ & $\begin{array}{c}\text { Pericardial- } \\
\text { effusion }\end{array}$ & Treatment & Prognosis & Ref. \\
\hline 1 & $29 / \mathrm{F}$ & 5 years & $?$ & + & - & PSL & Dead & 6 \\
\hline 2 & $33 / \mathrm{F}$ & 2 years & + & - & - & PSL, FFP, VIN, AP & Alive & 7 \\
\hline 3 & $60 / \mathrm{F}$ & 4 months & - & - & + & PE, PSL, Ig & Dead & 8 \\
\hline 4 & $48 / \mathrm{F}$ & 12 years & + & + & - & PE, PSL, AP & Alive & 9 \\
\hline 5 & $40 / \mathrm{F}$ & 2 years & - & + & - & PE. PSL, VIN, AP & Dead & 10 \\
\hline 6 & $73 / \mathrm{F}$ & 6 months & + & + & + & PE, PSL & Dead & 11 \\
\hline 7 & $64 / \mathrm{F}$ & 8 years & + & + & - & PE, PSL & Dead & 12 \\
\hline 8 & $35 / \mathrm{F}$ & 9 years & + & + & - & PE, PSL, Ig, AP & Alive & 13 \\
\hline 9 & $73 / \mathrm{F}$ & 10 years & + & + & - & PE, PSL & Dead & 14 \\
\hline 10 & $24 / \mathrm{F}$ & 1 year & - & - & - & PE, PSL & Alive & 15 \\
\hline 11 & $15 / \mathrm{M}$ & Simultaneously & - & - & - & PE, PSL, VIN, CyA & Alive & 16 \\
\hline 12 & $42 / \mathrm{F}$ & 4 years & + & - & - & PSL, FFP & Alve & 17 \\
\hline 13 & $47 / \mathrm{F}$ & 14 years & + & - & + & PE, PSL & Dead & Case 1 \\
\hline 14 & $61 / \mathrm{F}$ & 2 months & + & + & + & PE, PSL & Dead & Case 2 \\
\hline
\end{tabular}

MCTD, mixed connective tissue disease ; PSL, prednisolone ; FFP, fresh frozen plasma ; VIN, vincristine ; AP, anti-platelet agents ; PE, plasma exchange ; Ig immunoglobulin ; CyA, cyclosporine A. 
high shear stress, which causes platelet thrombi to form due to a tendency of platelets to aggregate and because of elevated plasma levels of $\mathrm{vWF}^{20)}$. Also, interference with the attachment of ADAMTS13 to endothelial cells in vivo (for example, as a result of ADAMTS13-receptor blockade by other types of autoantibodies) might cause TTP ${ }^{18)}$. Because the prevalence of TTP in CTD patients is relatively high ( $1 \%$ to $6 \%$ of patients with CTD $)^{22)}$, injury of endothelial cells and the presence of autoantibodies may be important factors that cause CTD-TMA.

In our cases, although we could not measure ADAMTS13 activity immediately after development of TTP, ADAMTS13 activity was normal or only moderately decreased, and ADAMTS13 neutralizing antibodies were not detected in either patient. Since neutralizing antibodies were not detected, the patients were treated mainly by PE, and immunosuppressants, except for prednisolone, were not given. These treatments were clearly not effective.

Pericardial effusion was observed in both patients. The presence of chronic pericardial effusion in SSc patients has been reported to suggest the existence of microvascular abnormality ${ }^{23)}$ and poor prognosis, often complicated by renal failure ${ }^{24)}$. However, especially in case 2 , we cannot completely rule out the possibility that cardiac effusion was caused by heart failure. Cardiac effusion might suggest the existence of microvascular injury in our cases. It was also reported that platelets transport high amounts of vascular endothelial growth factor (VEGF) in systemic sclerosis patients ${ }^{25}$. Although we did not measure serum VEGF levels in our two patients, VEGF might be important in the pathogenesis of pericardial effusion and systemic edema in TTP patients.

In summary, we have reported 2 MCTD patients complicated with TTP. TTP is a rare but life-threatening complication in MCTD patients. In order to clarify the pathogenesis of this condition, and to establish useful predictors and effective treatments, more cases need to be accumulated.

\section{CONFLICT AND INTEREST STATEMENT}

None

\section{REFERENCES}

1. Franchini M. Thrombotic microangiopathies: An update. Hematology, 11 : 139-146, 2006.

2. Furlan M, Robles R, Galbusera M, Remuzzi G, Kyrle PA, Brenner B, et al. von Willebrand factor- cleaving protease in thrombotic thrombocytopenic purpura and hemolytic uremic syndrome. N Engl J Med, 339 : 1578-1584, 1998.

3. Gilliland BC. Systemic Sclerosis (Scleroderma) and Related Disease. In Kasper DL, Braunwald E, Fauci AS, Hauser SL, Longo DL, Jameson JL, editors. Harrison's principles of Internal Medicine. $16^{\text {th }}$ ed. New York: McGraw-Hill ; 2005. p. 1979-1990.

4. Hamasaki K, Mimura T, Kanda H, Kubo K, Setoguchi K, Satoh T, et al. Systemic lupus erythematosus and thrombotic thrombocytopenic purpura: a case report and literature review. Clin Rheumatol, 22 : 355-358, 2003.

5. Manadan AM, Harris C, Block JA. Thrombotic thrombocytopenic purpura in setting of systemic sclerosis. Semin Arthritis Rheum, 34 : 633-638, 2004.

6. ter Borg EJ, Houtman PM, Kallenberg CG, van Leeuwen MA, van Ryswyk MH. Thrombocytopenia and hemolytic anemia in a patient with mixed connective tissue disease due to thrombotic thrombocytopenic purpura. J Rheumatol, 15 : 1174-1177, 1988.

7. Paice EW, Snaith ML. Thrombotic thrombocytopenic purpura occurring in a patient with mixed connective tissue disease. Rheumatol Int, 4 : 141-142, 1984

8. Saito Y, Moriyama H, Saito N, Honma N, Arakawa M. An autopsy case of MCTD, which developed refractory muscle weakness, associated with thrombotic thrombocytopenic purpura and lactic acidosis (in Japanese). J Chubu Rheum Assoc, 24 : 142-143, 1993.

9. Ito H, Sueyoshi A, Saito M, Kakazu N, Nagahara H. A case of thrombotic thrombocytopenic purpura with mixed connective tissue disease (in Japanese). Naika, 81 : 794-796, 1998.

10. Poullin P, Lefevre P, Durand JM. Mixed connective tissue disease with hemolytic anemia and severe thrombocytopenia due to thrombotic thrombocytopenic purpura. Am J Hematol, 61: 275, 1999.

11. Aoki K, Miura R, Sato H, Anzai M, Kobayashi N, Maruyama $\mathrm{H}$, et al. An autopsy case of MCTD, complicated with thrombotic thrombocytopenic purpura (in Japanese). Kanto riumachi, 34 : 3849, 2001.

12. Kato A, Suzuki Y, Fujigaki Y, Yamamoto T, Yonematsu K, Miyajima H, et al. Fatal complication of thrombotic microangiopathy in a patient with mixed connective tissue disease. Rheumatol Int, 22 : 122-125, 2002.

13. Ishihara T, Kuroda T, Murakami S, Hasegawa H, Ito S, Nakano M, et al. A case report of TTP in a patient with MCTD (in Japanese). J Chubu 
Rheum Assoc, 35 : 158-159, 2004.

14. Kuroda T, Matsuyama K, Nakatsue T, Murakami S, Hasegawa H, Nakayuma H, et al. A case of mixed connective tissue disease complicated with thrombotic thrombocytopenic purpura. Clin Rheumatol, 26 : 101-104, 2007.

15. Kajita N, Muro Y, Tomita A, Hirashima K, Matsushita T, Naoe T, et al. Thrombotic thrombocytopenic purpura with mixed connective tissue disease. A case report (in Japanese). Arerugi, 58 : 567-572, 2009.

16. Jayabose S, Levendoglu-Tugal O, Ozkayanak MF, Chao CP, Cuccovia B, Sandoval C. Use of vincristine and cyclosporine in childhood thrombotic rhrombocytopenic purpura. J Pediatr Hematol Oncol, 25 : 412-415, 2003.

17. Souto Filho JT, de Barros PV, da Silva AM, Barbosa FA, Ribas GF. Thrombotic thrombocytopenic purpura associated with mixed connective tissue disease : A case report. Case Report Med, 2011 : 953890, 2011.

18. Moake JL. Mechanisms of disease, thrombotic microangiopathies. N Engl J Med, 347 : 589-600, 2002.

19. Fujimura Y, Matsumoto M. Registry of 919 patients with thrombotic microangiopathies across Japan : Database of Nara medical university during 1998-2008. Inter Med, 49 : 7-15, 2010.

20. Matsuyama T, Kuwana M, Matsumoto M, Isonishi
A, Inokuma S, Fujimura Y. Heterogeneous pathogenic processes of thrombotic microangiopathies in patients with connective tissue diseases. Thromb Haemost, 102 : 371-378, 2009.

21. Watanabe H, Kaise S, Takeda I, Matsuzaki H, Kobayashi H, Nishimaki T, et al. Anti-endothelial cell antibodies in the sera of patients with mixed connective tissue disease - the clinical significance. Fukushima J Med Sci, 43 : 13-28, 1997.

22. Sato T, Hanaoka R, Ohshima M, Miwa Y, Okazaki Y, Yajima N, et al. Analysis of ADAMTS13 activity and its inhibitor in patients with thrombotic thrombocytopenic purpura secondary to connective tissue diseases: Observations in single hospital. Clin Exp Rheumatol, 24 : 454-485, 2006.

23. Gladman DD, Gordon DA, Urowitz MB, Levy HL. Pericardial fluid analysis in scleroderma (systemic sclerosis). Am J Med, 60 : 1064-1068, 1976.

24. Satoh M, Tokuhira M, Hama N, Hirakata M, Kuwana M, Akizuki M, et al. Massive pericardial effusion in scleroderma: A review of five cases. Br J Rheumatol, 34 : 564-567, 1995.

25. Solanilla A, Villeneuve J, Auguste P, Hugues M, Alioum A, Lepreux S, et al. The transport high amount of vascular endothelial growth factor by blood platelets underlines their potential contribution in systemic sclerosis angiogenesis. Rheumatology, 48 : 1036-1044, 2009. 